\title{
Health Locus of Control and Health Behaviours in Lung Cancer Patients
}

\author{
Medha Tripathi $^{1}$, H. S. Asthana ${ }^{2}$, A. K. Asthana ${ }^{3}$
}

\section{ABSTRACT}

With growing number of cancer survivors, health behaviours may become relevant not only to prevention of cancer recurrence and improved survival, but also to quality of life and the reduction of risk for other chronic diseases. Given the importance of relatively good health as a basis for many of life's pursuits and pleasures, it is understandable that cancer patients would seek to avoid illness and death, and indefinitely seek to obtain a state of better health. The present study aimed at studying the relationship of health behaviours and health locus of control in patients diagnosed with lung cancer. Results show that internal health locus of control was positively correlated with health promoting behaviours and negatively correlated with health impairing behaviours and external health locus of control was negatively correlated with health promoting behaviours and positively correlated with health impairing behaviours.

Keywords: Lung Cancer, Health Behaviours, Health Locus Of Control

GLOBOCAN, the international agency for research on cancer has estimated that there will be approximately 1.7 million new cases of cancer in India by 2035. Lung cancer is the most common type of cancer found (11.7\% of all cancer) in Indian population and is the third largest cause of mortality due to cancer in India. It has become a key public health issue which requires immediate action.

With advancements in the field of medicine and treatment, there is a rapid increase in number of cancer patients. The risk of recurrence, secondary cancers and effects of therapy or treatment is greater for cancer patients. There are also increased risks of co morbid chronic conditions. The lifestyle choices by cancer patients during and after their treatment greatly affect treatment

\footnotetext{
${ }^{1}$ Research scholar, Department of Psychology, Banaras Hindu University, India

${ }^{2}$ Professor, Department of Psychology, Banaras Hindu University, India

${ }^{3}$ Professor, Department of Radiotherapy and Radiation Medicine, Institute of Medical Sciences, Banaras Hindu University, India

*Responding Author

(C) 2016 I M Tripathi, H Asthana, A Asthana; licensee IJIP. This is an Open Access Research distributed under the terms of the Creative Commons Attribution License (http://creativecommons.org/licenses/by/2.0), which permits unrestricted use, distribution, and reproduction in any Medium, provided the original work is properly cited.
} 


\section{Health Locus of Control and Health Behaviours in Lung Cancer Patients}

recovery, recurrence, and general health. A large amount of research has linked health risk behaviours in cancer patients with increased levels of morbidity and mortality.

The 2003 American Cancer Society (ACS) Guide for Informed Choices, Nutrition and Physical Activity During and After Cancer Treatment noted that current data support "probable" and "possible"' benefit for several health behaviours, such as eating more fruits and vegetables and less saturated fat and increasing physical activity (Brown et al. 2003). While the literature remains tentative and conflictual (Gapstur and Khan 2007) there is evidence that, following cancer, increased levels of exercise and healthier diets, including increased fruit and vegetable intake, are related to lower recurrence and lengthened survival (Holmes et al. 2005; Meyerhardt et al. 2008; Pierce et al. 2007) and possibly reduced risk of developing second cancers (Doyle et al. 2006).

The growing number of cancer patients is causing a greater need to have an insight into the health behaviours of cancer patients as health behaviours such as smoking, drinking, poor dietary choices and inactivity are causing more than half of cancer deaths. Thus, a better understanding of their health status and health behaviours to improve and maintain their health status is the need of hour.

In describing health behaviours it is common to distinguish health enhancing behaviours from health impairing behaviours. Health impairing behaviours have harmful effects on health or otherwise predispose individuals to disease. Such behaviours include smoking, excessive alcohol consumption, and high dietary fat consumption. In contrast, engagement in health enhancing behaviours conveys health benefits or otherwise protects individuals from disease. Such behaviours include exercise, fruit and vegetable consumption, and condom use in response to the threat of sexually transmitted diseases.

One of the most important aspects of cancer patients is the practice of positive health behaviours as they help in lowering the risks of recurrences, secondary cancers and other comorbid conditions. Researches in this field have shown that health behaviour change interventions targeting cancer patients have been encouraging, where interventions mainly focused on targeting exercise, diet, and smoking. Exercise interventions have been effective in improving symptoms, fitness and quality of life, and most importantly, not to result in adverse outcomes. Dietary interventions have been successful in promoting changes in dietary intake and associated biomarkers, with interim results from a recent reduced-fat dietary intervention in breast cancer patients suggesting an influence on recurrence. Smoking cessation interventions have shown variable quit rates, but for the most part, they have been similar to or better than interventions targeting non-cancer samples. 


\section{Health Locus of Control and Health Behaviours in Lung Cancer Patients}

Rotter in his social learning theory proposed that potential for behaviour to occur in any specific psychological situation is a function of the expectancy that the behaviour will lead to a particular reinforcement in that situation and the value of that reinforcement. The expectancy regarding the occurrence of outcomes relates to whether the person perceives the outcome to be under the control of him/her or outside forces. Based on the belief that measures of specific expectancy should be used, the concept of health locus of control was proposed which refers to the degree to which people perceive themselves as having control on their own health. A belief of external control exists when reinforcement is seen as following some action, but not contingent on the action, and therefore beyond personal control. The reinforcement is interpreted as the result of luck, chance, fate, or the influence of others who have power over their lives. The belief is termed internal control When reinforcement is perceived as contingent on behaviour, and therefore under personal control. Research on locus of control characterizes persons with internal control perceptions as better able to seek and use information in problem solving, more likely to exert efforts to control environment, less susceptible to social influence, more oriented to achievement, and more willing to approach, use, and benefit from help from authority figures.

Number of studies has shown that people with high internal health locus of control will engage in health-promoting activities, while the reverse will be true of those with strong beliefs in chance (Wallston, 1992). Yet despite many investigations, the literature remains inconclusive (Norman \& Bennett, 1996; Reich, Erdal, \& Zautra, 1997). Strickland (1978) reviewed early work using unidimensional internal-external expectancy rather than multidimensional models, and argued that precautionary behaviours such as not smoking were more common among individuals with strong internal beliefs. Inverse associations between smoking and internal locus of control have been confirmed in some subsequent studies. Regular physical exercise has been associated positively with internal health locus of control and negatively with chance and powerful other locus (Calnan, 1989; Duffy, 1997; Norman, Bennett, Smith, \& Murphy, 1997), but null findings have also been reported (Callaghan, 1998; Laffrey \& Isenburg, 1983; Rabinowitz, Melamed, Weisburg, Tal, \& Ribak, 1992).

Healthy food choices have also shown inconsistent associations with health locus of control (Bennett, Moore, Smith, Murphy, \& Smith, 1994;Duffy, 1997; Schank \& Lawrence, 1993). Results for relationships between alcohol consumption and internal health locus of control are mixed (Bennett, Norman, Murphy, Moore, \& Tudor-Smith, 1998; Callaghan, 1998; Calnan, 1989). Strickland (1978) and Wallston (1992) have argued that internal health locus of control will exert a stronger influence over health behaviour among individuals who value their health highly compared with those with other priorities in life, but this notion has received only limited support (Bennett et al., 1997, 1998; Norman et al., 1997; Wurtele, Britcher, \& Saslawsky, 1985). In one study among a large sample of young adults from 18 European countries, the odds of five healthy behaviours were $40 \%$ greater in individuals with high as compared to those with low internal health locus of control. In contrast, external health locus of control was usually reported to be associated with adverse health-related behaviours, such as smoking or excessive alcohol 


\section{Health Locus of Control and Health Behaviours in Lung Cancer Patients}

consumption or poorer health outcomes. Chance health locus of control was also reported as related to unfavourable health-related behaviours, such lower sports activity, fewer medical teeth check-ups, and less health-related information-seeking. Similarly, in a study by Steptoe and Wardle (2001), high chance health locus of control was reported to be associated with more than $20 \%$ reductions in the likelihood of 6 healthy behaviours.

Wallston and Wallston (1982) have suggested that in medical situations where only a little personal control is possible, patients are more likely to be reliant on external sources of control, such as doctors or powerful others (e.g. family), than on internal sources. Evidence from previous studies found different health locus of control orientations between healthy persons and physically ill persons. Healthy college or adult samples tended to have a higher internal health locus of control and a lower external health locus of control, whereas chronically ill patients (e.g. chronic obstructive pulmonary disease, hypertension and cancer) tended to have higher external health locus of control (Wallston and Wallston, 1981). High external health locus of control among chronically ill patients may have advantages for their emotional adjustment, as patients who do not try to control their condition, may be able to minimize their level of frustration. For example, a study among cancer chemotherapy patients who received progressive muscle relaxation and/or biofeedback training to alleviate the side effects of treatment found that patients with a high external health locus of control showed greater improvement on measures such as pulse rate, blood pressure and depression than patients with a high internal health locus of control (Burish et al., 1984).

However, the results of previous studies have not always been conclusive. Some studies reported that health locus of control failed to explain variance in health-related habits beyond that explained by basic personality factors, although it was a significant predictor of health attitudes. Internal health locus of control was reported to be associated also with adverse behaviours, such as more frequent smoking, and unrelated to a range of positive health-related behaviours (sports activity, healthy diet, teeth check-ups, medical check-ups or seeking information about health issues). In a study of patients with chronic low back pain, none of the scores for the three domains of health locus of control revealed any significant associations with adherence to therapy. In patients with cancer undergoing mindfulness-based intervention, chance health locus of control but also internal health loci of control were found to be significantly lower after treatment. It may be that this literature reflects the genuine state of affairs, with health locus of control having little consistent association with health behaviours.

The purpose of this study was to assess the relationship between health behaviours and health locus of control in lung cancer patients. It was hypothesized that there will be a positive correlation between internal health locus of control and health promoting behaviours and a negative correlation between external health locus of control and health promoting behaviours. It was also hypothesized that external health locus of control will be positively correlated with 


\section{Health Locus of Control and Health Behaviours in Lung Cancer Patients}

health impairing behaviours and external health locus of control will be negatively correlated with health promoting behaviours.

\section{METHODOLOGY}

\section{Design and Participants}

The study used a cross-sectional design. A non-experimental, correlational design was used to evaluate the relationship between health behaviours and health locus of control in patients diagnosed with lung cancer. The study was conducted on 103 patients. Mean age of the patients was $54.00(\mathrm{SD}= \pm 10.81)$ years, ranging from 35 to 78 .

\section{Procedure}

The sample was chosen through purposive sampling from various hospitals providing cancer treatment in Varanasi region. Patients were included in the sample if they had a physician made single diagnosis of lung cancer. All the participants were able to read, comprehend, and write Hindi. Patients were suffering from the disease for at least 6 months. Patients having comorbid conditions were not included in the study. Further, patients receiving alternative medicine were also not included in the study. Written informed consent was taken from all the participants as well as their caregivers. The patients were given questionnaires to fill along with the demographic details.

\section{Tools}

Demographic details covered age, sex, marital status, and educational qualifications, of the patients. Medical details included stage of disease, time of diagnosis, comorbidity, and mode of treatment.

Health behaviours were assessed through the adapted version of Health Behaviour Scale (Risk and Health Behaviour Scale) developed by Renner and Schwarzer (2005). It is a 27 items scale. The scale consists of four dimensions including nutrition, physical activities, tobacco consumption and alcohol consumption. The chronbach's alpha for the scale is .70.

Health locus of control was assessed using Multidimensional Health Locus of Control (Form C) developed by Wallston and Wallston (1978). The scale consists of mainly three dimensions namely internal health locus of control, chance health locus of control and powerful others health locus of control. It is an 18 item scale. The chronbach's alpha for the scale is .81.

\section{Statistical analysis}

At first, descriptive analyses were done. In order to evaluate the relationship between health behaviours and health locus of control, Pearson's $r$ correlation coefficient was calculated. Statistical significance was established at the level of $\mathrm{P} \leq .05$. The data were processed using SPSS 20.0 software. 


\section{RESULTS}

The present study was conducted on 77 males and 26 females diagnosed with lung cancer.. Most of the participants were married. Literate and educated participants were included in the study. Out of 103 patients, 43 were diagnosed with advanced stage of disease and 60 were diagnosed with early stage lung cancer. The descriptive analysis of this study is shown below:

Table 1 shows the demographic data of the investigated patients diagnosed with lung cancer.

\begin{tabular}{|l|c|c|}
\hline & N & \% \\
\hline Sex & & \\
\hline Male & 77 & 74.7 \\
Females & 26 & 25.2 \\
\hline Marital status & 92 & \\
\hline Married & 8 & 89.32 \\
Unmarried & 2 & 7.7 \\
Widow/widower & 1 & 1.9 \\
Separated & & 0.9 \\
\hline Education & 51 & \\
\hline School level education & 52 & 49.51 \\
Higher education & & 50.48 \\
\hline Stage of disease & 60 & 58.25 \\
\hline Early stage & 43 & 41.74 \\
\hline Advanced stage & & \\
\hline
\end{tabular}

Table 2 shows the mean and SD of the health behaviour total and its dimensions.

\begin{tabular}{|l|c|c|c|}
\hline & N & Mean & SD \\
\hline Nutrition & 103 & 41.86 & 6.05 \\
\hline Physical activities & 103 & 8.65 & 4.10 \\
\hline Tobacco consumption & 103 & 13.60 & 6.75 \\
\hline Alcohol consumption & 103 & 10.94 & 3.25 \\
\hline
\end{tabular}

Table 3 shows the mean and SD of the dimensions of health locus of control

\begin{tabular}{|l|c|c|c|}
\hline & N & Mean & SD \\
\hline Internal health locus of control & 103 & 23.79 & 7.62 \\
\hline Chance health locus of control & 103 & 28.46 & 6.98 \\
\hline Powerful others health locus of control & 103 & 27.73 & 6.28 \\
\hline
\end{tabular}


Health Locus of Control and Health Behaviours in Lung Cancer Patients

Table 4 shows the correlation between the dimensions of health behaviours and the dimensions of health locus of control

\begin{tabular}{|l|l|l|l|l|}
\hline & Nutrition & $\begin{array}{l}\text { Physical } \\
\text { activities }\end{array}$ & $\begin{array}{l}\text { Tobacco } \\
\text { consumption }\end{array}$ & $\begin{array}{l}\text { Alcohol } \\
\text { consumption }\end{array}$ \\
\hline $\begin{array}{l}\text { Internal health locus of } \\
\text { control }\end{array}$ & .082 & .186 & -.338 & -.193 \\
Chance health locus of & $(.20)$ & $(.03)$ & $(.000)$ & $(.02)$ \\
control &. .282 & -.308 & .239 & .094 \\
\hline $\begin{array}{l}\text { Powerful others health } \\
\text { locus of control }\end{array}$ & $-.002)$ & $(.001)$ & $(.008)$ & $(.17)$ \\
\hline
\end{tabular}

Pearson's $r$ correlation coefficient was calculated to evaluate the relationship between health behaviours and dimensions of health locus of behaviours. The results show that there exist a positive correlation between internal health locus of control and nutrition $(r(103)=.082, \mathrm{p}=.20)$ though the relationship was not found statistically significant. Positive correlation between physical activities and internal health locus of control was found significant $(r(103)=.136$, $\mathrm{p}=.03$ ). Internal health locus of control was significantly negatively correlated with health impairing behaviours namely tobacco consumption $(r(103)=-.338, \mathrm{p}=.0001)$, and alcohol consumption $(r(103)=-.193, \mathrm{p}=.02)$

Chance health locus of control was significantly negatively correlated with health promoting behaviours namely, nutrition $(r(103)=-282, \mathrm{p}=.002)$ and physical activities $(r(103)=-.308$, $\mathrm{p}=.001)$. Chance health locus of control was significantly positively correlated with tobacco consumption $(r(103)=.239, \mathrm{p}=.008)$. Though there exist a positive correlation between chance health locus of control and alcohol consumption $(r(103)=.094, \mathrm{p}=.17)$, the relationship is not statistically significant.

Powerful others health locus of control was significantly negatively correlated with nutrition $(r(103)=-.346, \mathrm{p}=.000)$ and physical activities $(r(103)=-.375, \mathrm{p}=.000)$ and significantly positively correlated with tobacco consumption $(r(103)=.307, \mathrm{p}=.001)$. The correlation between powerful others health locus of control and alcohol consumption $(r(103)=.141, \mathrm{p}=.07)$ though positively correlated, was not found statistically significant.

\section{DISCUSSION}

Health promoting behaviours, such as proper nutrition and adequate physical activities are of great importance for patients suffering from lung cancer. Several studies have reported that many cancer patients engage in unhealthy behaviours such as poor diet, smoking, alcohol consumption which may lead to cancer recurrence, development of secondary cancers and other chronic diseases. 


\section{Health Locus of Control and Health Behaviours in Lung Cancer Patients}

The results show that the mean score for physical activities is lowest among all the mean scores of various dimensions of health behaviours. This may be due to the lower capacity of lungs due to illness. Nutrition has the highest score showing that patients despite of their illness and treatment side effects try to consume proper nutrition.

Our study also revealed that the mean score of chance exceeded the mean score of the other two subscales. This indicates that the population studied has somewhat more characteristics of external locus of control than internal locus of control. The findings of the current study show that patients with lung cancer tend to attribute their illness to external sources of control, namely: physicians, significant others, and chance.

Interesting results were found in our study with respect to the associations between health behaviour and health locus of control. Nutrition and physical activities were positively correlated with internal health locus of control. Tobacco consumption and alcohol consumption were positively correlated with chance and powerful others health locus of control. Thus, the finding supports the universality of the claim that external health locus of control should be linked to unfavourable outcomes in health behaviours and internal health locus of control should be linked to favourable health behaviour outcomes.

One possible explanation for this finding is related to the nature of cancer and its treatment process. Despite of advances in the treatment processes most of the patients diagnosed with any form of cancer still consider it as a threat to their lives. The perceived uncontrollable nature of cancer and the uncertainty of treatment outcomes might reduce patients' beliefs in personal control over their illness. In addition, the majority of patients involved in the current study require long-term cancer treatment. This situation may lead to an increased belief in external forces among patients, i.e. the doctor, powerful others (e.g. family members), and chance in the determination of their health condition.

Even though this study had statistically significant results, there were limitations. The choice of our sample might and probably did affect the findings we obtained. Most studies on healthrelated behaviour have utilized non clinical population-based samples. Future research should analyse the relationship in other chronic illnesses as well. A comparison can also be made between health behaviours and health locus of control of patients with various chronic illnesses. Another limitation was the fact that participants were only assessed once during the treatment. As stated previously, they were just moving out of the recovery phase and this may have affected some of their responses. Responses may have been different if the population was studied six months to one year after surgery. Another important limitation of our study, which should be taken into account when analysing the results, is a lack of precise control of depression and anxiety levels. Although patients with a history of major mental disorder were excluded from participation, this does not preclude that some patients may have had undiagnosed or subclinical 


\section{Health Locus of Control and Health Behaviours in Lung Cancer Patients}

levels of depression and anxiety, and this in turn might affect the results through introduction of an important source of variance into the scores of both health-behaviours and health locus of control. Future research should probably analyse the possible mediating effects of these mental conditions on the association between health behaviour and health locus of control.

\section{CONCLUSION}

Much literature has focused on locus of control and health behaviours independently, but only a limited amount tie the two variables together. This study looked at these two important variables in a population of lung cancer patients undergoing treatment. Results showed a positive correlation between internal locus of control and health promoting behaviours and negative correlation between health impairing behaviours and positive correlation between external health locus of control and health impairing behaviours and negative correlation with health promoting behaviours were consistent with the literature. Clearly stated, patients who believe that their actions will have positive outcomes will exhibit more health protecting behaviours. Since it is known that risk factor reduction decreases the incidence of secondary cancers and other chronic illnesses, health promoting behaviours by these patients should lead to a decreased cancer risk overall. This study adds further support to the importance of locus of control when trying to predict health behaviours in a population of cancer patients undergoing treatment. There are implications for advanced practice as well as nursing research and the health care delivery system. Further research as reviewed above will only serve to strengthen and expand upon results obtained.

\section{REFERENCES}

American Cancer Society (2004) Cancer facts and figures. http ://www.cancer. org/downloads/STT/CAFF_fi nalplTsecured.pdf

Bennett, P., Moore, L., Smith, A., Murphy, S., \& Smith, C. (1994). Health locus of control and value for health as predictors of dietary behaviour. Psychology and Health, 10(1), 41-54.

Bennett, P., Norman, P., Moore, L., Murphy, S., \& Tudor-Smith, C. (1997). Health locus of control and value for health in smokers and nonsmokers. Health Psychology, 16(2), 179.

Bennett, P., Norman, P., Murphy, S., Moore, L., \& Tudor-Smith, C. (1998). Beliefs about alcohol, health locus of control, value for health and reported consumption in a representative population sample. Health Education Research, 13(1), 25-32.

Brown, J. K., Byers, T., Doyle, C., Courneya, K. S., Demark- Wahnefried, W., Kushi, L. H., et al. (2003). Nutrition and physical activity during and after cancer treatment: An American Cancer Society guide for informed choices.ca A Cancer Journal for clinicians,53(5) ,268-291

Burish TG, Carey MP, Wallston KA, et al (1984). Health locus of control and chronic disease: An external orientation may be advantageous. Journal of Social Clinical Psychology, 2, 326-32.

(C) The International Journal of Indian Psychology, ISSN 2348-5396 (e)| ISSN: 2349-3429 (p) | 28 


\section{Health Locus of Control and Health Behaviours in Lung Cancer Patients}

Callaghan P. (1998) Social support and locus of control as correlates of UK nurses' health related behaviours. Journal of Advanced Nursing,(28), 1127- 1133

Calnan, M. ( 1989) Control over health and patterns of health-related behaviour. Social Science Medicine, 29(14),131-136.

Cohen, M., \& Azaiza, F. (2007). Health-promoting behaviors and health locus of control from a multicultural perspective. Ethnicity and Disease, 17(4), 636.

Conner, M., \& Norman, P., (1996). Predicting Health Behaviors. Buckingham, UK: Open University Press

Doyle, C., Kushi, L. H., Byers, T., Courneya, K. S., Demark-Wahnefried, W., Grant, B., \& Andrews, K. S. (2006). Nutrition and physical activity during and after cancer treatment: an American Cancer Society guide for informed choices. CA: a cancer journal for clinicians, 56(6), 323-353.

Duffy M. E., Rossow, R., Herandez, M. (1996) Correlates of health-promotion activities in employed Mexican American women. Nursing Research, 45(15),18-24.

Gapstur, S. M., \& Khan, S. (2007). Fat, fruits, vegetables, and breast cancer survivorship. Journal of the American Medical Association, 298(3), 335-336.

Holmes, M. D., Chen, W. Y., Feskanich, D., Kroenke, C. H., \& Colditz, G. A. (2005). Physical activity and survival after breast cancer diagnosis. Jama, 293(20), 2479-2486.

Iskandarsyah, A., de Klerk, C., Suardi, D. R., Soemitro, M. P., Sadarjoen, S. S., \& Passchier, J. (2014). Psychosocial and cultural reasons for delay in seeking help and nonadherence to treatment in Indonesian women with breast cancer: A qualitative study. Health Psychology, 33(3), 214.

Janowski, K., Kurpas, D., Kusz, J., Mroczek, B., \& Jedynak, T. (2013). Health-related behavior, profile of health locus of control and acceptance of Illness in patients suffering from chronic somatic diseases. PloS one, 8(5), e63920

Laffrey SC, Isenburg M. (1983). The relationship of internal locus of control, value placed on health, perceived importance of exercise, and participation in physical activity during leisure. International Journal of Nursing Studies,20,187-196.

López, M. C. N., López-Roig, S., \& Pastor, M. Á. (2007). Control beliefs in cancer: A literature review. Anuario de psicología/The UB Journal of psychology, 38(3), 333-355.

Meyerhardt, J. A., Niedzwiecki, D., Hollis, D., Saltz, L. B., Hu, F. B., Mayer, R. J., et al. (2008). Association of dietary patterns with cancer recurrence and survival in patienti with stage III colon cancer. Obstetrical and Gynecological Survey, 63(2), 94-96.

Norman P, Bennett P, Smith C, Murphy S (1998) Health locus of control and health behaviour. Journal of Health Psychology, 3(2), 171-180.

Pierce, J. P., Stefanick, M. L., Flatt, S. W., Natarajan, L., Sternfeld, B., Madlensky, L.,et al. (2007). Greater survival after breast cancer in physically active women with high vegetable-fruit intake regardless of obesity. Journal of Clinical oncologv, 25(17), 23452351. 


\section{Health Locus of Control and Health Behaviours in Lung Cancer Patients}

Pinto, B. M., Eakin, E., \& Maruyama, N. C. (2000). Health behaviors after cancer. Annals of Behavioral Medicine, 22 (1), 38-52.

Pinto, B., M., \& Trunzo, J., J. (2005). Health behaviors during and after a cancer diagnosis. American Cancer Society, 104(11), 2614-2623.

Rabinowitz, S., Melamed, S., Weisberg, E., Tal, D., \& Ribak, J. (1992). Personal determinants of leisure-time exercise activities. Perceptual and motor skills, 75(3), 779-784.

Reich, J. W., Erdal, K. J., \& Zautra, A. J. (1997). Beliefs about control and health behaviors. In Biennial Conference on Community Research \& Action, Div 27 of the American Psychological Assn., 3rd, Jun, 1991. Plenum Press.

Schank M.J., Lawrence, D.M. (1993). Young adult women: Lifestyle and health locus of control. Journal of Advanced Nursing, 18,1235-1241

Steptoe A, Wardle J (2001) Locus of control and health behaviour revisited: a multivariate analysis of young adults from 18 countries. British Journal of Psychology, 92, 659- 672.

Strickland, B. R. (1978). Internal-external expectancies and health-related behaviors. Journal of consulting and clinical psychology, 46(6), 1192.

Wallston BD, Wallston KA (1978) Locus of control and health: a review of the literature. Health Education Monograph, 6 (2), 107-117.

Wallston, K.A. (1992). Hocus-Pocus, the focus isn't strictly on locus: Rotter's social learning theory modified for health. Cognitive Therapy and Research, 16(2), 183-199.

Wurtele, S. K., Britcher, J. C., \& Saslawsky, D. A. (1985). Relationships between locus of control, health value, and preventive health behaviors among women. Journal of Research in Personality, 19(3), 271-278.

How to cite this article: M Tripathi, H Asthana, A Asthana (2016), Health Locus of Control and Health Behaviours in Lung Cancer Patients, International Journal of Indian Psychology, Volume 3, Issue 3, No. 11, DIP: 18.01.192/20160303, ISBN: 978-1-365-21307-6 